\title{
AHP Yöntemi Kullanarak ERP Sistemlerinin Karşılaştırılması ve Uygun Sistemin Belirlenmesi
}

\author{
Comparison of ERP and Defining the Optimum ERP System Using AHP Method
}

\author{
Semih ÖZEL ${ }^{1}$ (D), Anıl TÜRKEL ${ }^{2}$ \\ ${ }^{1}$ Marmara Üniversitesi, Endüstri Mühendisliği Bölümü, 34722, İstanbul, Türkiye \\ ${ }^{2}$ Marmara Üniversitesi, Endüstri Mühendisliği Bölümü, 34722, İstanbul, Türkiye
}

\begin{abstract}
$\ddot{O} \mathbf{z}$
İşletmelerde kaynak planlaması (ERP) kullanılması hem işletmenin sürdürülebilirliği hem de ürün hizmet başarısı açısından önemli bir süreçtir. Kaynakların en verimli şekilde kullanılması özellikle ikinci sanayi devriminden sonra işletmelerdeki en önemli konulardan biri olmuş, bu amaçla üretim kaynak planlaması ve iş̧ zekası çözümleri geliştirilmiştir. Günümüzde endüstri 4.0 olarak anılan 4. sanayi devrimi ile özellikle bilgi işlem teknolojilerindeki ilerlemeler, kaynak planlaması çözümlerinin daha etkin ve yaygın olarak kullanılmasını sağlamış ve işletmelerin rekabetçi güçlerini büyük oranda artırmıştır. Özellikle kurumsallaşmayı önemsemiş işletmeler bilgi işlem altyapıların ERP sistemleri ile tümleşik hale getirerek daha sağlıklı bir ürün hizmet verimliliği elde edebilmektedirler. Ürün ve hizmet üretiminde ERP sistemlerinin kullanılması kadar işletmenin özelliklerine uygun bir ERP programının seçilmesi de önemlidir. Yanlış ERP seçimi, iş akışlarının durmasından dolayı maliyet kayıplarına sebep olmakla birlikte ciddi vakit kaybına da yol açabilmektedir.

$\mathrm{Bu}$ çalışmada işletme ölçütleri temel alınarak en uygun ERP programının seçilebilmesi için Analitik Hiyerarşi Prosesi (AHP) yaklaşımı kullanılmıştır. Literatür taraması ve alan uzmanlarının önerileri ile temel ölçütler belirlenmiş ve AHP yöntemi kullanılarak ölçütlerin ağırlıklandırılması sağlanmıştır. Uygulamada karar matrisleri tasarlanırken gerçek ERP konusunda uzman görüşleri göz önünde bulundurulmuştur. Firmalar için ERP seçiminde hangi ölçütlerin daha önemli olacağı ve karar sürecinde ne şekilde bir yöntem izlenmesi gerektiği çalışmada sunulmuştur.
\end{abstract}

Anahtar Kelimeler: İşletmelerde Kaynak Planlaması (ERP), Analitik Hiyerarşi Prosesi (AHP), Karar verme

\begin{abstract}
The use of resource planning (ERP) in enterprises is an important process for both the sustainability of the enterprise and the product service performance. The most efficient use of resources has been one of the most important issues in the enterprises, especially after the second industrial revolution. For this purpose, production resource planning and business intelligence solutions have been developed. With the 4th industrial revolution, today called industry 4.0, advances in computing technology in particular have made resource planning solutions more efficient and widespread and have increased the competitive power of enterprises to a large extent. In addition, discussion was held with consultants of related ERP companies. As a result of all these efforts, the most effective ERP software was tried to be chosen. Deciding the right ERP software is one of the critical factors that will affect success of enterprises. Wrong decision can lead to unnecessary costs and loss of time. Even worse, it can cause unpredictable stops of workflow within the company. In the course of the work done, it was tried to assist the managers in their decisions in the direction of the needs and expectations of the company using AHP method.

In this study, the Analytic Hierarchy Process (AHP) approach was used to select the most appropriate ERP program based on business criteria. Basic criteria were determined by literature review and field experts' recommendations and weighting of criteria was achieved by using the AHP method. Expert opinions on real ERP have been taken into account when designing decision matrices in practice. It was presented in the study which criteria will be more important for ERP selection for companies and how the decision process should be followed.
\end{abstract}

Keywords: Enterprise Resource Planning (ERP), Analytic Hierarchy Process (AHP), Decision Making 


\section{GíRiș}

Günümüzde rekabetçi ekonomi ile birlikte karmaşı iş zekası ve kaynak planlama sistemleri (ERP) işletmelerde stratejik anahtar bir konuma gelmiş ve yaygın bir şekilde kullanılmaya başlamıştır. Firmalarda yürütülen her türlü projenin başarılı olmasını etkileyen en büyük etkenin ERP sistemlerinin yaygın kullanılması olduğu düşünülmektedir. Son zamanlarda ERP uygulamalarının kullanımı ile firmalar finansal şeffaflık, etkin tedarik zinciri süreçleri ve minimum insan kaynağı kullanımı gibi önemli gelişmeler ve değişimleri gerçekleştirebilmektedirler. Günümüz rekabetçi iş dünyasında, iş zekası ve kaynak planlaması çözümleri ile yöneticiler işletmelerinin sektördeki durumunu çok daha iyi analiz ederek daha uygun stratejiler geliştirebilmektedirler [4].

ERP kurumların tüm tedarik süreçlerini bütünleşik tek bir sistem üzerinden yönetilmesini sağlayan ve bünyesinde üretim, satın alma, tedarik zinciri, insan kaynakları gibi çeşitli modüller barındıran bir iş zekası yazılımıdır [10]. ERP amaçlarının en temelinde tüm süreçlerin ortak bir platform üzerinden yönetilmesi ve bütünlüğün sağlanması vardır. İşletme ile ilgili her türlü bilginin farklı kaynaklardan toplanarak analiz edilmesi ve raporlanması temel fonksiyonlarından biridir. Firmalar günümüzdeki yoğun rekabetçi ortamda olabildiğince iş süreçlerini daha verimli yönetmek, doğru raporlamalar, analizler almak zorundadırlar. En küçük işletmeden en büyük işletmeye kadar bu durum geçerliliğini korumaktadır.

İş süreçlerini verimli yönetmenin ve doğru raporlamalar almanın firmalara azımsanmayacak katkıları olduğu açıktır. Bu katkılar genel olarak en az maliyetle aynı ürünün veya hizmetin tedarik edilmesi, iyi planlama ile üretimin dengelenmesi, stokların ve maliyetlerin anlık ve doğru şekilde görülebilmesi, mevcut ve doğru stoklarla MRP planlaması yapılabilmesi, sevkiyatın iyi planlanarak son gönderim tarihlerine uyulması, tedarik zincirinin daha verimli yönetilmesi, nakit akışının etkin bir şekilde yönetilmesi, gelir gider analizleri ile bütçenin planlanması, satış öncesi ve satış sonrası hizmetlerin takibi, tüm belgelerin dijital ortamlarda saklanması, iş süreç ve onaylarının dijital ortamlarda yönetilmesi şeklinde sayılabilir. ERP yazılımı kullanmayan firmalarda raporlar ve analizlerin her birim için ayrı ayrı şekilde tutularak hazırlanması, gereksiz yinelemelere ve dolayısı ile hem enerji hem de gereksiz zaman kaybına neden olabilmektedir. ERP yazılımı kullanmayan firmalar veri girişi gerektiren işlemleri manuel yapmak durumundadırlar ve her seferinde bu durum tekrarlanmaktadır. ERP bu veri girişlerini otomatikleştirerek zaman kaybını engeller ve çalışanların daha önemli süreçler için vakit harcayabilmelerini sağlar [13].

ERP sistemleri firmanın tüm üretim, satın alma, satış gibi temel tedarik süreçlerinin kolaylıkla takip edilebilmesini ve raporlanabilmesini sağlamak açısından da önemlidir. Ayrıca ERP bünyesindeki modüller ile firmanın tüm departmanları arasındaki bilgi akışını entegre ederek tek bir bilgi kaynağı haline getirmekte ve süreçlerin hızlanmasını sağlamaktadır[14]. Günümüzde bu durum işletmelerin büyüklüğüne göre büyük veri olarak tanımlanmış ve endüstri 4.0 çalışmalarında yönetilmesi ve yeni çözümlerin geliştirilmesini gerekli hale getirmektedir. ERP sistemleri belli çaptaki büyük verinin daha kolay şekilde yönetilmesini sağlayabilmektedir.

Ayrıca firmalar CRM SRM modülleri ile hem müşterileri hem satıcıları ile entegre bir şekilde çalışabilmektedir. $\mathrm{Bu}$ da işletmeler arası bilgi akışının doğruluğunu ve hızını önemli bir şekilde etkiler. ERP firma içinde yapılan neredeyse tüm işlemlerin çok detaylı bir şekilde raporlanabilmesine olanak sağar. Üretim, satın alma, satış gibi tüm tedarik adımları raporlanabilir ve çeşitli analizler üretilebilir. Yapılan raporlamalar geriye dönük olduğu gibi iş zekası gibi modüller sayesinde geleceğe dönük raporlar da alınabilmektedir. ERP yazılımın doğru bir şekilde entegre edilmesi firmanın müşterilerine çok daha kısa sürede dönüş yapması, hem yurtiçi hem yurtdışı müşteriler ile hızlıca etkileşime geçerek, problem veya talebin ERP sistemi ile hızlıca çözüm üreterek müşteri ilişkilerinin güçlenmesini sağlamaktadır[15].

Veri güvenliği açısında ERP sistemleri kendi bünyesinde barındırdığı yetkilendirme mekanizmaları ile firmaların veri güvenliği problemlerinin önüne geçebilmektedir. ERP sistemleri çalışma prensibi olarak tek bir sunucu kullanmaktadır. Bu da firmanın verilerin tutarlılığını ve güvenliğini artırmaya yardımcı olur. Çünkü alınan yedeklemeler sayesinde olası bir güvenlik tehdidinin önüne geçilir [16].

ERP sisteminin bütünleşik yapısını kullanmak IT harcamalarının önemli ölçüde önüne geçmesi için önemli bir faktördür. Tek bir sistem kullanmak eğitim harcamamalarını da düşürerek çok sayıda sistemin öğrenilmesinden oluşacak zaman kaybını da önlemektedir. Bununla birlikte tek bir sistemin kullanılması raporlama ve analiz tarafinda birçok kolaylık sağlamaktadır. Kişiye özel raporların yaratılması çok daha basite indirgenir. Bu da IT harcaması olmadan raporların oluşturulabileceği anlamına gelecektir.

Genel olarak bakıldığında ERP sistemleri, günümüz bilişim teknolojileri alanındaki önemli gelişmelerden biri olmuştur. ERP sistemleri malzeme yönetiminden muhasebeye, üretimden satın almaya, dağıtımdan finans ve insan kaynaklarına kadar olan tüm süreçlerin uyumlu bir işbirliğinin sağlanması ve işletme faaliyetlerinin en iyi şekilde yürütebilmesi açısından kritik öneme sahiptir [6]. 
Kurumsal kaynak planlamanın işletmelere birçok avantajı olmakla birlikte uygulama aşamasında başarısızlık oranları yüksektir. Bunun birinci sebebi işletmeye uygun ERP sistemlerinin geliştirilmemesi ve dolayısı ile birçok noktada sıkıntıların oluşmasıdır. Hazır sistemlerin kullanılması yerine işletmenin yapısına uygun sitemlerin tasarlanması gerekmektedir. Böylece uygulama aşamasında ortaya çıacak problemleri en aza indirgeyerek zamanla yeni güncellemeler ile sistemin mükemmelleştirilmesi sağlanabilmektedir. Dolayısı ile uygun ERP sisteminin seçilmesi başarı için en önemli etkenlerden biridir. İkinci önemli dezavantajlı durum ise işletmedeki kullanıcıların ERP kullanımı konusunda yeterli hassasiyeti göstermemeleri konusunda oluşmaktadır. $\mathrm{Bu}$ durumun sistemi kullanacak çalışanlara uygun eğitimlerin verilmesi ve yetkililerin bu konudaki 1srarlı takipleri ile düzeltilebileceği görülmüş̧ür. Uygun sistemin seçilmesi bu konuda teknik destek noktasında güvenilir firmalar ile çalışılması önemli hale gelmektedir. Dolayısı ile ERP sisteminin uygunluğu ve teknik destek önemli kriterler olarak öne çıkmaktadır [17], [3].

Kurumsal kaynak planlaması yazılımlarının ve firmaları için karar verme süreci hem alternatiflerin fazla olması hem de uzun süreli bir proje olması ve bunların yanında maliyetin gözetilmesinin gerekliliği karmaşık ve hassas bir süreçtir. $\mathrm{Bu}$ alanda onlarca yazılım firması ve ERP sisteminin olduğu düşünülürse, bir işletme için en uygun ERP sisteminin seçilmesi kritik ve önemlidir. [12], [5]. ERP sistemlerinin hem tasarlanması hem de uygulanması açısından zaman alıcı ve maliyetli süreçlerdir. Kurulum zorluğu, üretim kaybı ve kaynakların kullanımı açısından bakıldığında geri dönüşü olmayan bir yatırım olarak değerlendirilmektedir [18], [3].

Günümüzdeki rekabetçi koşullarda ERP geçiş kararı ve ERP sisteminin kullanımı önemli bir karardır. Türkiye ve dünya pazarı incelendiğinde birçok ERP sistemi arasından en etkili yazılımı seçmek ise daha da önemli bir karardır. Bu noktada AHP yönteminden faydalanarak ERP seçiminde en doğru kararın verilmesinin sağlanabileceği düşünülmüştür.

$\mathrm{Bu}$ çalışmada öncelikle ERP sistemlerinin önemi anlatılmış ve işletmelere faydaları detaylı bir şekilde açıklanmıştır. Bununla birlikte işletmelerin ERP sistemi seçimlerinin en önemli kararlardan biri olduğu vurgulanmış ve bu amaçla AHP yönteminin kullanılabileceği belirtilmiştir. AHP ile seçim yapılması için gerekli kriterlerin literatür incelemeleri ve bu alandaki uzman kişilerden faydalanılarak belirlenmesi sağlanmış ve AHP tekniği kullanılarak kriterlerin önceliklendirilmesi hesaplanmıştır. Son olarak piyasada yaygın kullanılan dört ERP sisteminin karşılaştırılması yapılarak işletmeler için ERP seçiminde nasıl bir yol izlenebileceği sunulmuştur.

\section{LITTERATÜR İNCELEME}

İşletmelerde süreçler karmaşıklaştıkça ERP türü yazılımların kullanılması artmış ve daha çok ihtiyaca yönelik ürünler ön plana çıkmıştır. Bu tür sistemlere olan ihtiyacı karşılamak üzere birçok firma bu alanda faaliyet göstermeye başlamış ve günümüz bilişim teknolojileri kullanılarak yeni sistemler geliştirilmiştir. Bunun sonucunda aralarından işletme için en verimli sistemin seçilmesi önemli bir değerlendirme ve karar süreci haline gelmiştir. [1]. İşletmenin geleceği için önemli sonuçları olabilecek bu kararın gelişigüzel şekilde ya da tavsiye ile alınamayacağı açıktır. Kurumsal kaynak planlama sistemine karar verme sürecini etkileyen belli başlı faktörler mevcuttur. Aşağıda sıralanan faktörler göz önüne alınarak değerlendirme kriterlerinin belirlenmesi gerekmektedir [12].

- Piyasada ERP yazılım ürünlerinin azlığı,

- Sürekli gelişen bilişim teknolojileri,

- Donanım ve yazılım sistemleri arasında oluşan uyumsuzluklar,

- Yazılımları oluşturan fonksiyonların karmaşıklığı,

- Kullanıcı bilgi deneyim eksikliği [7].

$\mathrm{Bu}$ açıdan değerlendirme kriterlerinin tanımlanması öncelikle önemlidir. Bu aşamada literatürde daha önce yapılmış çalışmaların incelenmesi bilimsel altyapının kurulması açısından önemlidir. $\mathrm{Bu}$ alanda yapılan çalışmalar arasından seçilenler aşağıda görüleceği şekilde özetlenmiştir.

Wei ve arkadaşları (2005), yaptıkları çalışmada ERP programı seçiminde 6 temel ve 14 alt faktör belirlemişlerdir. Bu süreçte dikkat edilmesi gereken en önemli faktörlerin ERP yazılımı ve satıcı firma ile ilgili faktörler olduğunu belirtmişlerdir. Yazılım faktörleri olarak sırası ile maliyet, uygulama için gerekli zaman, fonksiyonellik, kullanım kolaylığı, esneklik ve güvenilirlik olarak belirtilmiştir. Yazılım firmasına ait faktörler ise marka tanınırlı̆̆ı, teknik destek yeteneği ve hizmet sürdürülebilirliği olarak ifade edilmiştir [12].

Teltumbde (2000) çalı̧̧masında, ERP yazılımı seçmek için kavramsal bir çerçeve oluşturmuş ve bu süreçte kullanılabilecek 10 önemli kriter belirlemiştir. Bu kriterler sırasıyla teknoloji, stratejik kararlar, değişim yönetimi, risk yönetimi, uygulanabilirlik, işlevsellik, firma kimliği, esneklik, maliyet ve fayda oranı olarak belirlenmiştir [9]. 
Bueno ve Salmeron (2008) tarafindan yapılan bir çalışmada, bulanık (Fuzzy) AHP yöntemini kullanarak ERP yazılımı karar verilmesinde kullanılabilecek 17 kriter belirlemiştir. Bu kriterler sırası ile endüstride uygulama imkanı, sistem güvenliği, uyum kolaylığı, güvenilirlik, modülerlik, ihtiyaç belirleme, bilgi sağlama yeteneği, sezgisellik, maliyet, danışmanlık ücreti, bakım masrafları, genel gereksinimler, uzman ekip ihtiyacı, ortalama uygulama süresi, karmaşık parametre durumu, planlama, nesnel kavramların tanımlanması olarak değerlendirilmiştir [3].

Benzer bir çalışmada, Ahn ve Cho (2008), bir tekstil firması için ERP sistemi karar verilmesine yönelik etkili faktörler tanımlamıştır. Çalışmalarında bu faktörleri 5 stratejik, 20 alt faktör olarak ayırmış ve Şekil 1 de görüleceği gibi işlevsellik, servis desteği, teknoloji, maliyet ve firmaya güven önemli stratejik faktörler olarak dikkate alınmıştır [1]. Diğer alt faktörler ilgili 5 stratejik faktör altında toplanmıştır.

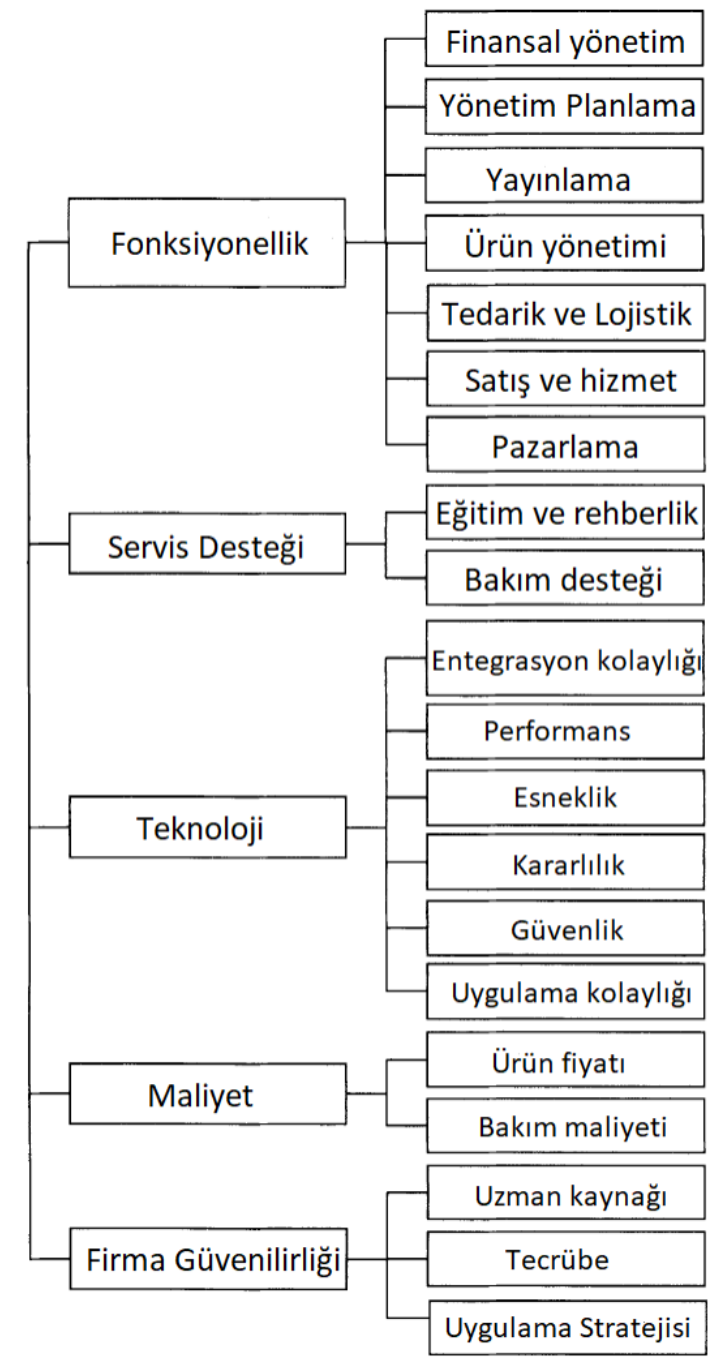

Şekil 1. ERP sistemi için değerlendirme kriterleri [1]

Şekil 1 de görülen kriterler benzetim tabanlı AHP yöntemi kullanılarak gruplandırma yapılmış ve gruplar karşılaştırılarak tüm kriterlerin ağırlık değerleri belirlenmiştir.

Karsak ve Özoğlu (2009), çalışmalarında benzer olarak ERP sistemi için karar verme kriterlerini Delphi ve Shannon Entropi yaklaşımı kullanarak belirlemişlerdir. Bu yaklaşım ile 3 temel kriterle birlikte her temel kriterin altında toplamda 15 kriter belirlenmiştir. Belirlenen temel kriterler maliyet, ürün kalitesi ve ERP geliştirici firma olarak sunulmuştur [5].

Ünal ve Güner (2009) yaptıkları çalışmada, AHP (Analitik Hiyerarşi Süreci) yöntemini kullanarak tekstil sektöründe yer alan bir işletme için alternatifler arasından en uygun ERP sistemi geliştiren firma için karar verme faktörlerinin belirlenmesi yapılmıştır. Faktörlerin belirlenmesinde yine sektör uzmanlarından, firma 
yöneticilerinden ve bu sistemleri kullanan çalışanların görüşlerinden faydalanmışlardır. Çalışmalarında kaynak planlama sisteminin belirlenmesinde kullanılabilecek 9 kritik faktör önermişlerdir. Önerilen bu faktörler sırası ile işlevsellik, uygulama kolaylığı, teknik destek, maliyet, güvenilirlik, tecrübe, esneklik, müşteri güveni ve geleceğe yönelik stratejiler olarak ifade edilmiştir [11].

Benzer olarak Perçin (2008) yaptığı çalışmada Analitik Network Süreci (ANP) yöntemi ile alternatifler arasından ERP yazılım sistemine karar verilmesinde 2 temel ve 12 alt faktör olmak üzere toplam 14 kriter belirlemiştir. Belirlenen bu 14 kriterden iki temel faktör olarak yazılım niteliği ve firma özellikleri ön planda tutulmuş, yazılım niteliği altında işlevsellik, strateji, esneklik, kullanım kolaylığı, uygulama süresi, maliyet ve güvenilirliktir alt faktör olarak sıralanmıştır. Firma özellikleri açısından güvenilirlik, tecrübe, bilinirlik, destek yeteneği ve uzman personel alt faktör olarak belirtilmiştir [8].

Son olarak Kumar ve Hillsgersberg (2000) çalışmalarında tedarikçi ve ERP sistem yazılımı için karar faktörleri olarak fonksiyonellik, güvenilirlik, işletmenin diğer sistemleri ile uyum, entegrasyon kolaylığı, marka, teknik destek, modülerlik, versiyon güncelleme, düşük maliyet ve iş süreçleri ile uyum şeklinde 10 temel faktör kullanılarak değerlendirilmiştir [6].

ERP sistemi seçim ve değerlendirme konusunda yapılan çalışmalara bakıldığında hemen hemen hepsinde maliyetin ana kriter olarak göz önüne alındığı görülmektedir. Maliyeti belirleyen temel unsurların dünyada tanınırlık durumu ve yaygın kullanımı olduğu görülmüştür. Dolayısı ile maliyetten sonra marka bilinirliği ve yaygın kullanım özelliği yine önemli bir faktör olarak belirlenmiştir. Bu iki faktörle birlikte sistemin kolay kullanılabilir olması, kolay entegrasyon ve eğitim teknik destek gibi faktörlerin ön plana çıktı̆̆ı görülmektedir.

Tablo 1. Literatür ERP seçim kriterleri

\begin{tabular}{|c|c|c|c|c|c|c|c|c|c|}
\hline & $\begin{array}{l}\text { Teltumdbe } \\
\text { (2000) }\end{array}$ & $\begin{array}{l}\text { Kumar } \\
\text { ve } \\
\text { Hillsgers } \\
\text { berg } \\
(2000)\end{array}$ & $\begin{array}{c}\text { Wei ve } \\
\text { diğerleri } \\
(2005)\end{array}$ & $\begin{array}{l}\text { Baki ve } \\
\text { Çakar } \\
(2005)\end{array}$ & $\begin{array}{l}\text { Ahn ve } \\
\text { Choi } \\
(2008)\end{array}$ & $\begin{array}{l}\text { Ünal ve } \\
\text { Güner } \\
\text { (2008) }\end{array}$ & $\begin{array}{c}\text { Bueno ve } \\
\text { Salmeron } \\
(2008)\end{array}$ & $\begin{array}{l}\text { Perçin } \\
(2008)\end{array}$ & $\begin{array}{l}\text { Karsak } \\
\text { ve } \\
\text { Özogul } \\
(2009)\end{array}$ \\
\hline Fonksiyonellik & $\sqrt{ }$ & $\sqrt{ }$ & $\sqrt{ }$ & & $\sqrt{ }$ & $\sqrt{ }$ & & $\sqrt{ }$ & $\sqrt{ }$ \\
\hline Maliyet & $\sqrt{ }$ & $\sqrt{ }$ & $\sqrt{ }$ & $\sqrt{ }$ & $\sqrt{ }$ & $\sqrt{ }$ & $\sqrt{ }$ & $\sqrt{ }$ & $\sqrt{ }$ \\
\hline Teknoloji & $\sqrt{ }$ & & $\sqrt{ }$ & $\sqrt{ }$ & & $\sqrt{ }$ & & $\sqrt{ }$ & $\sqrt{ }$ \\
\hline Marka İtibarı & & $\sqrt{ }$ & $\sqrt{ }$ & $\sqrt{ }$ & $\sqrt{ }$ & $\sqrt{ }$ & $\sqrt{ }$ & $\sqrt{ }$ & \\
\hline Destek ve Eğitim & & & $\sqrt{ }$ & $\sqrt{ }$ & & & $\sqrt{ }$ & $\sqrt{ }$ & \\
\hline Entegrasyon & & $\sqrt{ }$ & & $\sqrt{ }$ & $\sqrt{ }$ & & & $\sqrt{ }$ & \\
\hline İşlem Kolaylığ1 & & & $\sqrt{ }$ & & $\sqrt{ }$ & & & $\sqrt{ }$ & $\sqrt{ }$ \\
\hline Modülerlik & & & & & & & $\sqrt{ }$ & & \\
\hline $\begin{array}{l}\text { Danışmanlık } \\
\text { Hizmeti }\end{array}$ & & & $\sqrt{ }$ & $\sqrt{ }$ & & & $\sqrt{ }$ & & \\
\hline Servis Desteği & & $\sqrt{ }$ & $\sqrt{ }$ & $\sqrt{ }$ & $\sqrt{ }$ & $\sqrt{ }$ & & $\sqrt{ }$ & $\sqrt{ }$ \\
\hline Satıcı Ünvanı & $\sqrt{ }$ & & $\sqrt{ }$ & & $\sqrt{ }$ & & & & $\sqrt{ }$ \\
\hline Stratejik Uyum & $\sqrt{ }$ & & & & $\sqrt{ }$ & $\sqrt{ }$ & & $\sqrt{ }$ & \\
\hline Satic1 & & $\sqrt{ }$ & & $\sqrt{ }$ & $\sqrt{ }$ & $\sqrt{ }$ & & & \\
\hline Referans Risk & $\sqrt{ }$ & & & & & & & & \\
\hline
\end{tabular}

\section{III.ERP SEÇİMINDE KARAR VERME}

Genel olarak firmaların başarılarını etkileyen en önemli nedenlerden biri rekabetçi iş koşullarında alınan doğru ve güvenilir kararlar olmaktadır. Karar verme aşamasında hem alternatiflerin hem de seçim kriterlerinin çok sayıda olması karar sürecini çoğu zaman içinden çıkılamayacak bir duruma getirebilmektedir. Karar verme konusunda sezgisel yaklaşımlar yerine bilimsel yöntemlerin kullanılması başarılı bir değerlendirme için en önemli konulardan biridir. Bir tarafta çok sayıda alternatifler bulunurken diğer tarafta hem yazılımların özellikleri hem de işletmenin kendi şartları arasında ancak en uygun yöntem ya da yöntemler kullanılarak doğru bir sonuç elde edilmesi mümkündür. 
Karar verme süreci karar verici, alternatifler, ölçütler, çevresel şartlar, öncelikler ve kararın sonuçları gibi öğeler içermektedir. Süreç sonunda karar mekanizması mevcut seçenekler arasından seçim yaparak seçimlerin sıralanması ya da sınıflandırılmasını sağlamaktadır. Bu süreçte mekanizmanın işletilebilmesi için doğru kararların alınması için çok ölçütlü karar verme yöntemleri kullanılmaktadır. Belirli kriterlerin genelde ikili karşılaştırmalar esas alınarak belirli karar verme yöntemleri ile sayısal veriler kullanarak en doğru kararın verilmesi sağlanmaktadır [19]. Çok kriterli karar verme yöntemlerinden en çok kullanılanların AHP (Analitik Hiyerarşi Prosesi), Fuzzy AHP, TOPSIS (Technique for Order Preference by Similarity to Ideal Solution) ve ELECTRE olduğu görülmektedir [20], [21], [22], [23].

Bu çalışmada da ERP seçimi için karşılaştırma yapabilmek ve en etkin ERP yazılımın seçilmesinde esnasında firma yöneticilerine destek olabilmek adına AHP yöntemi kullanılmıştır.

1970’lerde geliştirilen AHP yöntemi birden çok kriter içeren karmaşık problemlerin çözümünde kullanılan bir karar verme yöntemi olarak ele alınmıştır. AHP, karar vericilerin problemleri, hedef, kriterler, alt kriterler ve alternatifleri arasındaki ilişkiyi gösteren ve bu kriterlerin önceliklendirmesi üzerine bir hiyerarşik yapıda modellenmesine olanak sağlamaktadır. AHP'nin en önemli özelliği karar vericinin hem öznel hem de nesnel düşüncelerini sürece dahil edebilmesi olmaktadır. Diğer ifade ile AHP, bilginin, tecrübenin, bireyin kendi düşüncelerinin ve önsezilerin mantıksal bir şekilde birleştirildiği bir yöntem olarak kullanılmasıdır. AHP geniş bir uygulama alanına sahiptir ve pazarlama, finans, eğitim, kamu politikaları, ekonomi gibi birçok alanda karar probleminde etkin olarak kullanılmıştır [24], [25], [26], [27].

Bu çalışmada inşaat sektöründe faaliyet gösteren 500 ün üzerinde çalışanı bulunan ve Türkiye'nin birçok bölgesindeki otoyol yapım projelerinde yer alan bir firma için ERP sistemi seçiminde gerekli olan kriterlerin belirlenmesi ve kriterlerin önceliklendirilmesi AHP yöntemi kullanılarak yapılmıştır. ERP seçiminde firmanın karar verme yetkinliğine sahip uzman çalışanlarına AHP yöntemi aracılığıyla doğru ERP sisteminin seçilmesi için ihtiyaç duyulan altyapı sunulmuş ve en uygun ERP sistemi önerilmiştir. Firmanın üretim, muhasebe ve finans departmanlarının yöneticileriyle yapılan görüşmelerde ERP yazılımlarının seçimine ilişkin literatür çalışmalarının sonuçları hakkında bilgi verilmiş ve bu doğrultuda işletmenin öncelikleri ve özellikleri dikkate alınarak karar verme için gerekli seçim kriterleri belirlenmiştir. Bu kriterlerin literatür ve işletmedeki önem durumuna göre sırasıyla Marka İtibarı, Teknoloji, Fonksiyonellik, Maliyet ve Teknik Destek ve Eğitim ana başlıkları ile karar kriterleri olarak kararlaştırılmıştır. Firma yöneticilerinin ERP yazılım seçimini etkileyen bu kriterleri göz önünde bulundurarak gerçek hayatta en çok tercih edilen 4 ERP firması alternatifleri arasından birini seçerek işletmeye kurulması sağlanacaktır. Alternatifler gerçek markalar olmasından dolayı çalışmada A firması, B firması, C firması ve D firması olarak gösterilmiştir. Gerçek firma isimleri ise seçimi yapacak işletme ile paylaşılmıştır. Problemin hiyerarşik yapısı aşağıda görülen Şekil 1 deki gibi oluşturulmuştur.

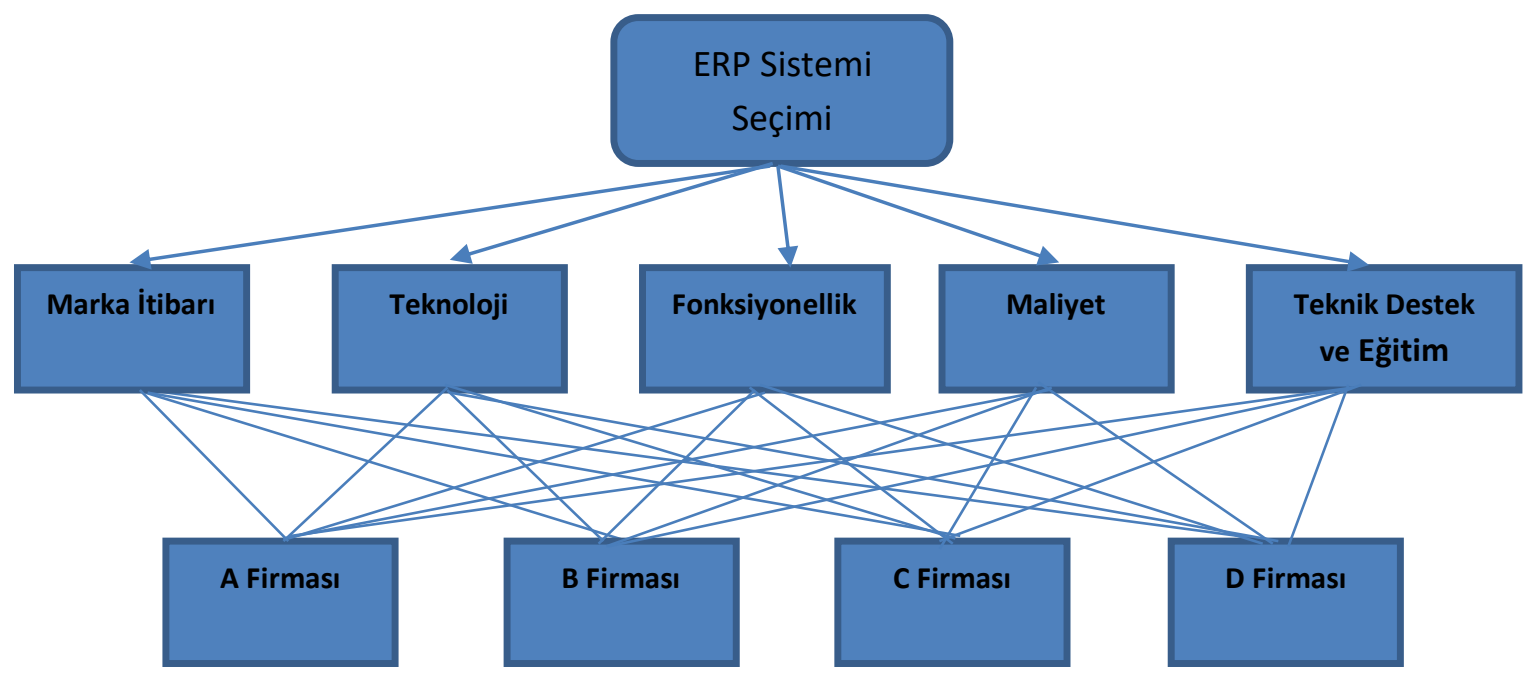

Şekil 2. ERP Sistemi Seçim için AHP yapısı

\subsection{Kriterlerin AHP ile Ăğırlıklandırılması}

Çalışmanın bir önceki kısımlarında hedefe uygun kriterler belirlenmiş ve alternatifler ile birlikte hiyerarşik yapı kurulmuştu. Bu kısımda seçim kriterlerinin ağırlıkları AHP yöntemi kurallarına göre belirlenecektir. Öncelikli olarak hiyerarşik yapı oluşturularak her kriterin göreceli önem derecesinin hesaplanması sağlanır. Kriterlerin göreceli önem dereceleri, ancak ikili karşılaştırmalar yapılarak yani iki kriterin birbirleriyle karşılaştırılması ile 
mümkün olmaktadır [3]. Daha önce belirlenmiş olan kriterlerin karşılaştırmaları alanında bilgi sahibi belli sayıda uzman tarafindan yapılmaktadır. Kriterler için ikili karşılaştırmalar matris tablosu aşağıda tablo 2 de gösterilmiştir. Karşılaştırma matrisi $n * n$ boyutlu bir kare matristir. Matrisin köşegeni üzerindeki matris bileşenleri aynı kriterlerin birbiriyle karşılaştırması yapılamayacağından 1 değerini alır.

Tablo 2. İkili karşılaştırma matrisi

\begin{tabular}{|l|l|l|l|l|}
\hline & 1. Kriter & 2. Kriter & 3. Kriter & n. Kriter \\
\hline 1. Kriter & $\mathrm{w}_{1} / \mathrm{w}_{1}$ & $\mathrm{w}_{1} / \mathrm{w}_{2}$ & $\ldots$ & $\mathrm{w}_{1} / \mathrm{w}_{\mathrm{j}}$ \\
\hline 2. Kriter & $\mathrm{w}_{2} / \mathrm{w}_{1}$ & $\mathrm{w}_{2} / \mathrm{w}_{2}$ & $\ldots$ & $\mathrm{w}_{2} / \mathrm{w}_{\mathrm{j}}$ \\
\hline 3. Kriter & $\ldots$ & $\ldots$ & $\ldots$ & $\ldots$ \\
\hline n. Kriter & $\mathrm{w}_{\mathrm{i}} / \mathrm{w}_{1}$ & $\mathrm{w}_{\mathrm{i}} / \mathrm{w}_{2}$ & $\ldots$ & $\mathrm{w}_{\mathrm{i}} / \mathrm{w}_{\mathrm{j}}$ \\
\hline
\end{tabular}

$$
A=\left[\begin{array}{cccc}
a_{11} & a_{12} & \ldots & a_{1 n} \\
a_{21} & a_{22} & \ldots & a_{2 n} \\
\cdot & & & \cdot \\
\cdot & & & \cdot \\
\cdot & & & \cdot \\
a_{n 1} & a_{n 2} & \ldots & a_{n n}
\end{array}\right]
$$

Karar verici Tablo 3 te görülen 1- 9 likert skalasını kullanarak kriterler arasındaki önem derecesini belirlemektedir. Bu skalada karşılaştırılan kriterlerin birbirleriyle arasındaki önem durumuna göre 1 ile 9 arasında bir puan alacaktır. 1 kriterler arasında eşit önemi gösteriyorken 9 en önemli düzeyi olarak skalada yer almaktadir. [24].

Tablo 3. 1-9 Likert Skalası (Saaty, 1980)

\begin{tabular}{|c|l|}
\hline Dereceler & \multicolumn{1}{|c|}{ Tanım } \\
\hline 1 & Eşit önemli \\
\hline 3 & Biraz önemli \\
\hline 5 & Önemli \\
\hline 7 & Çok önemli \\
\hline 9 & Son derece önemli \\
\hline $2-4-6-8$ & Ara/Ortalama Değerler \\
\hline
\end{tabular}

Karşılaştırma matrisi oluşturularak kriterlere sayısal değerler atanır ve sonrasında kriterler arasında göreceli önem dereceleri hesaplanır ve karşılaştırma matrisi elde edilmiş olunur. Karşılaştırma matrisinden sonraki adım normalizasyon matrisini oluşturmaktır. Normalizasyon genel olarak çok büyük ya da çok küçük değerlerin sorun oluşturmasını engellemek için tüm değerleri aynı formda ve birbirine yakın bir değere indirgemek için kullanılır. Böylece hesaplamalarda kolaylık sağlanmış ve değerler arasında ki karşılaştırma daha anlaşılabilir hale getirilmiş olunabilmektedir. Aşağıdaki formül 1 kullanılarak karşılaştırma matrisinde yer alan her hücre değerinin sütun toplamına bölünmesiyle normalize edilmiş yeni bir matris elde edilir.

$$
b_{i j}=\frac{a_{i j}}{\sum_{i=1}^{n} a_{i j}}
$$

Oluşturulan ikili karşılaştırma matrisinde göreceli önem derecesinin hesaplanmasında Saaty'nin (1994) belirlediği özvektör yöntemi kullanılmaktadır. Öz vektör ya da öncelik vektörü aşağıdaki formülle hesaplanmaktadır. Öz vektörün hesaplanmasında normalizasyon matrisinde yer alan her bir satırın ortalaması alınmıştır [28].

$$
W_{i}=\frac{1}{n} \sum_{j=1}^{n} \frac{a_{i j}}{\sum_{j=1}^{n} a_{i j}}
$$

Öz vektörün hesaplanması ile birlikte her kritere ait önem dereceleri belirlenir ve daha sonra karşılaştırma matrisinin tutarlılığı (CR) hesaplanır. CR değerinin hesaplanmasında amaç, karar vericilerin kriterler arasında 
karşılaştırma yaparken tutarlı davranılıp davranılmadığının tespit edilmesidir. CR değeri hesaplamalarda 0.10'dan büyük olduğu taktirde karar vericinin tutarsız olduğu anlaşılır ve yeni bir karar verici seçilerek matrise daha önce girilen değerler tekrar gözden geçirilir. CR sıfira ne kadar yakın olursa karar matrisinin tutarlılığının o oranda yüksek olduğu anlaşılacaktır [27]. Karşılaştırma matrisinin tutarlılığını hesaplamak için aşağıdaki formül kullanılmaktadır [24].

$$
\mathrm{CR}=\frac{\mathrm{CI}(\text { Tutarl } l \mathbf{l} l \mathbf{k} \text { Göstergesi) }}{\mathrm{RI}(\text { Rassall } l \mathbf{k} \text { Göstergeleri) }}
$$

Yukarıda 3 nolu formülde CI ile simgelenen tutarlılık göstergesi yine aşağıda gösterilen 4 nolu formül ile hesaplanmaktadır. CI hesaplarken formülde yer alan maksimum özdeğer ( $\lambda$ max) ise yine 5 nolu diğer bir formül yardımıyla hesaplanmaktadır.

$$
\mathrm{CI}=\frac{\lambda_{\max \square}-\mathbf{n}}{\mathbf{n}-\mathbf{1}}
$$

Oluşturulan karşılaştırma matrisinin her sütunu ile öncelik değerleri çarpılarak birlikte toplanır ve ağırlıklı toplam vektörünün oluşturulması sağlanır. Ağırlıklı toplam vektörünün her elemanı buna karşılık gelen öncelik değerine bölündükten sonra sonuç değerinin aritmetik ortalaması $\lambda$ max elde edilir. Rassallık göstergesi (RI) oranlarının, matris ölçüsüne göre değerleri aşağıdaki tabloda gösterilmiştir [29]. Rassallık göstergesi değeri ilk olarak 1980 yılında Saaty tarafından AHP yöntemi geliştirme çalışmasında kullanılmıştır. Kriter sayısına göre daha önce belirlenmiş RI değerleri kullanılarak tutarlılık testinin yapılabilmesi sağlanmaktadır. Bu çalışma için RI değeri kriter sayısı 5 olduğu için 1,12 olarak alınmıştır.

$$
\lambda_{\max }=\frac{1}{n} \sum_{\mathrm{i}=1}^{\mathrm{n}} \frac{(\mathrm{AW})_{\mathrm{i}}}{\mathbf{W}_{\mathrm{i}}}
$$

4. Rassallık göstergesi (RI) oranlarının, matris ölçüsüne göre değerleri

Tablo

\begin{tabular}{|c|c|c|c|c|c|c|c|c|c|c|c|c|c|c|c|}
\hline $\mathbf{N}$ & $\mathbf{1}$ & $\mathbf{2}$ & $\mathbf{3}$ & $\mathbf{4}$ & $\mathbf{5}$ & $\mathbf{6}$ & $\mathbf{7}$ & $\mathbf{8}$ & $\mathbf{9}$ & $\mathbf{1 0}$ & $\mathbf{1 1}$ & $\mathbf{1 2}$ & $\mathbf{1 3}$ & $\mathbf{1 4}$ & $\mathbf{1 5}$ \\
\hline $\mathrm{R} 1$ & 0,00 & 0,00 & 0,58 & 0,90 & 1,12 & 1,24 & 1,32 & 1,41 & 1,45 & 1,49 & 1,51 & 1,54 & 1,56 & 1,57 & 1,59 \\
\hline
\end{tabular}

\subsection{Problemin AHP Yöntemi ile Çözümü}

AHP yönteminde kriterleri belirledikten sonraki ilk aşama olan öncelik matrisinin belirlenmesinde ERP sistemi satın almak isteyen firmanın Üretim, Muhasebe, Finans ve IT gibi önemli departmanlarının yöneticilerinden oluşan 4 kişilik bir karar verici grubu oluşturulmuştur. Karar vericilerin matris oluşturması üzerine genelde üç tür uygulama mevcuttur. Tek bir karar verici olması halinde öncelik matrisi kriterler karşılaştırılarak likert skalasına göre puanlanır ve tutarlılığı kontrol edilir, tutarlılık yüksek çıkarsa tekrar gözden geçirilmek üzere uzmana gönderilir. Uzman sayısının birden fazla olduğu durumlarda üç yol izlenir. Birincisi uzmanlar bir araya gelerek kriterler üzerinde tartışır ve birlikte tek bir öncelik matrisi oluşturulur, ikinci yöntem ise her uzman tek tek kendi öncelik matrisini oluşturur ve tutarlılık oranı (CR) test edilir, tutarlılık \%10 altında ise ağırlıklar belirlenir ve ağırlık değerlerinin aritmetik ortalaması alınır. Üçüncü yöntem ise her uzmanın oluşturduğu öncelik matrisi değerleri geometrik ortalaması alınarak tek bir kare matris oluşturulur ve ağırlıklandırma yapılır. Böylece tek bir öncelik matrisi gibi ağırlıklar elde edilir [24],[25],[26].

$\mathrm{Bu}$ çalışmada işletmenin dört departmanından seçilen yönetici pozisyonundaki uzmanlar bir araya gelerek uzlaşma yöntemi ile literatür incelemeleri sonucunda karar verilen beş kriter üzerinde tartışarak karar almış ve tek bir öncelik matrisi oluşturulmuştur. Bu yöntemin kullanılma sebebi her bir uzmanın uzmanlık alanı farklı olduğundan bilgi birikimi ve tecrübelerin paylaşılarak en doğru değerlendirmenin yapılmasını sağlamaktır. Kriter sayısının azlığ 1 da bu yöntemin seçilmesinde etkili olmuştur. Öncelik matrisi değerleri hesaplamaları Excel de yapılmış öncelik matrisi "Göreceli Önem Dereceleri” belirlenmiştir. Bu dereceler satırdaki kriterin önem derecesinin sütundaki kriterin önem derecesine göre oranlanmasıyla oluşturulmuştur. Örneğin Marka İtibari kriterinin Teknoloji kriterine göre Göreceli Önem Derecesi Tablo 3'te belirtilen likert skalasına göre 2'dir. Teknoloji kriterinin Marka İtibari kriterine göre Göreceli Önem Derecesi ise 1/2² dir. Yani uzmanlara göre marka 
itibari teknolojiye göre daha önemli görülmüştür. Ayrıca sütun bazında Göreceli Önem Dereceleri toplanarak bir alt toplam elde edilmiştir. Bu alt toplam öz vektör hesaplamalarında kullanılacaktır. Öncelik matrisi Tablo 5 te gösterilmiştir.

Tablo 5. Öncelik Matrisi

\begin{tabular}{|c|c|c|c|c|c|}
\hline Öncelik Matrisi & 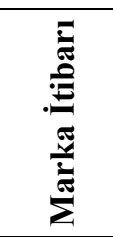 & 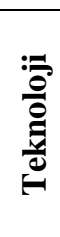 & 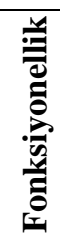 & 昰 & 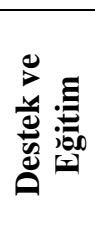 \\
\hline Marka İtibarı & 1 & 2 & 3 & 7 & 2 \\
\hline Teknoloji & 0,5 & 1 & 2 & 2 & 5 \\
\hline Fonksiyonellik & 0,3333 & 0,5 & 1 & 2 & 2 \\
\hline Maliyet & 0,1429 & 0,5 & 0,5 & 1 & 2 \\
\hline \multirow[t]{2}{*}{ Destek ve Eğitim } & 0,5 & 0,2 & 0,5 & 0,5 & 1 \\
\hline & 2,4762 & 4,2 & 7 & 12,5 & 12 \\
\hline
\end{tabular}

Öncelik matrisi oluşturulduktan sonra değerlerin normalize edilmesi gerektiği bir önceki bölümde anlatılmıştır. Dolayısıyla aşağıda Tablo 6 da normalizasyon işlemi yapılmış ve her bir göreceli önem derecesinin alt toplama bölünmesi ile kriter bazında normalize edilmiş değerler elde edilmişti. Örneğin 0,4038 değeri Tablo 5 te görülen birinci satır ve birinci sütunun kesiştiği değer ile marka itibarı sütunundaki değerlerin toplamına bölünmesi yani 1 / 2,4762 şeklinde hesaplanarak 0,4038 olarak elde edilmiştir.

Her bir kriterin elde ettiği ağırlık katsayısının aritmetik ortalaması ilgili kriterin ağırlık katsayısı olarak Tablo 7 de ayrıca gösterilmiştir. Hesaplanan ağırlık katsayıları ERP firmalarının toplam puanının hesaplamasında kullanılacaktır. Örneğin 0,407 final ağırlık katsayısı $(0,4038+0,4762+0,4286+0,56+0,1667) / 5$ şeklinde aritmetik ortalama alınarak hesaplanmıştır.

Tablo 6. Göreceli Önem Derecelerinin Alt Toplam Oranları

\begin{tabular}{|l|c|c|c|c|c|c|}
\hline $\begin{array}{c}\text { Önem } \\
\text { Derecelerinin Alt } \\
\text { Toplam Oranları }\end{array}$ & $\begin{array}{c}\text { Marka } \\
\text { İtibarı }\end{array}$ & Teknoloji & Fonksiyonellik & Maliyet & $\begin{array}{c}\text { Destek ve } \\
\text { Ĕgitim }\end{array}$ & $\begin{array}{c}\text { Öncelik vektörü/ } \\
\text { Ăğırlık }\end{array}$ \\
\hline Marka İtibarı & 0,4038 & 0,4762 & 0,4286 & 0,56 & 0,1667 & $\mathbf{0 , 4 0 7 1}$ \\
\hline Teknoloji & 0,2019 & 0,2381 & 0,2857 & 0,16 & 0,4167 & $\mathbf{0 , 2 6 0 5}$ \\
\hline Fonksiyonellik & 0,1346 & 0,119 & 0,1429 & 0,16 & 0,1667 & $\mathbf{0 , 1 4 4 6}$ \\
\hline Maliyet & 0,0577 & 0,119 & 0,0714 & 0,08 & 0,1667 & $\mathbf{0 , 0 9 9 0}$ \\
\hline Destek ve Eğitim & 0,2019 & 0,0476 & 0,0714 & 0,04 & 0,0833 & $\mathbf{0 , 0 8 8 9}$ \\
\hline & 1,000 & 1,000 & 1,000 & 1,000 & 1,000 & \\
\hline
\end{tabular}

Tablo 7. Her bir kriter için hesaplanmış katsayılar

\begin{tabular}{|l|c|}
\hline Kriterler & $\begin{array}{c}\text { Ăğırlık } \\
\text { Katsayıları }\end{array}$ \\
\hline Marka İtibarı & $\mathbf{0 , 4 0 7 1}$ \\
\hline Teknoloji & $\mathbf{0 , 2 6 0 5}$ \\
\hline Fonksiyonellik & $\mathbf{0 , 1 4 4 6}$ \\
\hline Maliyet & $\mathbf{0 , 0 9 9 0}$ \\
\hline Destek ve Eğitim & $\mathbf{0 , 0 8 8 9}$ \\
\hline
\end{tabular}


Kriterlerin ağırlıkları belirlendikten sonra daha önceki kısımda da anlatıldığı gibi tutarlılığın test edilmesi gerekmektedir. Tutarlılık analizi için CR = CI / RI formülü kullanarak önce CI hesaplanmış ve daha sonra beş kriter için belirlenmiş olan RI katsayısına bölünerek tutarlılık değerli elde edilmiştir. Yukarıda hesaplanan katsayılar ve öncelik matrisi değerleri kullanılarak CI değeri için öncelikle Lambda max $\left(\boldsymbol{\lambda}_{\max }\right)$ Excel de hesaplanmış ve 5,391 olarak bulunmuştur. Böylece CI değeri 0,098 olarak elde edilmiştir. Tutarlılık formülünde CI ve RI değerleri kullanılarak tutarlılık CR değeri bu çalışma için $\mathbf{0 , 0 9}$ olarak tespit edilmiştir. Görüleceği gibi tutarlılık değeri 0,1 den küçük olduğu için uzmanların değerlendirmelerinin oldukça tutarlı olduğu söylenebilmektedir.

Kriterlerin ağırlıklandırılması sağlandıktan sonra artık alternatifler ile karşılaştırılması yapılarak belirlenen kriter ağırlıklarına göre hangi alternatifin daha önemli olduğu tespit edilebilecektir. Bu aşamada yapılacak işlemler tamamen kriterlerin ağırlıklarının belirlenmesinde kullanılan yöntem ile aynı olup aynı hesaplamalar yolu ile bu sefer alternatiflerin ağırlık yani göreceli önem dereceleri tespit edilecektir. Firmalar arası karşılaştırmayı ERP sistemleri konusunda uzman bir kişi tarafından piyasada en çok tanınan dört ERP yazılım sağlayıcı firması göz önüne alınarak yapılmıştır.

Tablo 8 de Marka İtibarı kriteri için alternatif ERP firmaları arasında karşılaştırma yapılmış ve aynı hesaplamalar kullanılarak öncelik matrisi oluşturulmuştur. Diğer dört kriter için de (Teknoloji, Fonksiyonellik, Maliyet, Destek ve Eğitim) dört alternatif ERP firmaların karşılaştırmaları tek tek yapılmış ve alternatifler arasında ki ağırlıklar belirlenmiştir. Çalışmada sadece marka itibarı kriteri için alternatif ERP firmalarının öncelik matrisi hesaplaması Tablo 8 de gösterilmiştir. Aynı şekilde Tablo 9 da göreceli önem dereceleri ve Tablo 10 da final katsayıları görülmektedir. Benzer olarak diğer dört kriter de alternatiflerle karşılaştırılmış ve hesaplamaları yapılmıştır.

Tablo 8. Marka itibari için alternatif firmaların öncelik matrisi

\begin{tabular}{|c|c|c|c|c|}
\hline Marka İtibarı & 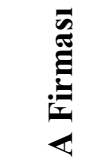 & 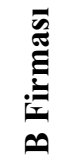 & 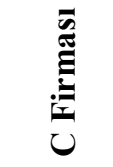 & $\stackrel{\bar{E}}{\tilde{E}}$ \\
\hline A Firması & 1 & 3 & 5 & 2 \\
\hline B Firması & 0,3333 & 1 & 0,3333 & 2 \\
\hline C Firması & 0,2 & 3 & 1 & 2 \\
\hline \multirow[t]{2}{*}{ D Firması } & 0,5 & 0,5 & 0,5 & 1 \\
\hline & 2,0333 & 7,5 & 6,8333 & 7 \\
\hline
\end{tabular}

Tablo 9. Alternatif ERP firmalarının göreceli önem dereceleri

Tablo 10. Alternatiflerin final katsayıları

\begin{tabular}{|c|c|c|c|c|}
\hline $\begin{array}{c}\text { Önem } \\
\text { Derecelerinin } \\
\text { Alt Toplam } \\
\text { Oranları }\end{array}$ & 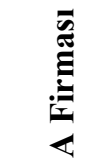 & 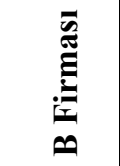 & 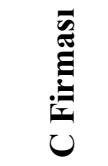 & 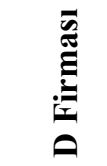 \\
\hline A Firması & 0,4918 & 0,4 & 0,7317 & 0,2857 \\
\hline B Firması & 0,1639 & 0,1333 & 0,0488 & 0,2857 \\
\hline C Firması & 0,0984 & 0,4 & 0,1463 & 0,2857 \\
\hline \multirow[t]{2}{*}{ D Firması } & 0,2459 & 0,0667 & 0,0732 & 0,1429 \\
\hline & 1,000 & 1,000 & 1,000 & 1,000 \\
\hline
\end{tabular}

\begin{tabular}{|l|c|}
\hline Marka İtibarı & $\begin{array}{l}\text { Puanların } \\
\text { Aritmetik } \\
\text { Ortalaması }\end{array}$ \\
\hline A Firması & 0,477 \\
\hline B Firması & 0,158 \\
\hline C Firması & 0,233 \\
\hline D Firması & 0,132 \\
\hline & 1,000 \\
\hline
\end{tabular}

Değerlendirme kriterlerinin final ağırlık katsayıları ve her bir alternatif ERP firmasının bu kriterler için elde ettikleri puanların aritmetik ortalaması hesaplanarak final puanları elde edilmiştir. Final puanları her kriterin ağırlık katsayısının ERP firmalarının elde ettiği puanın aritmetik ortalaması ile çarpılması ve tüm kriterler için toplanması ile elde edilmiştir. Örneğin A firmasının ağırlık puanı, $(0,407 * 0,477)+(0,260 * 0,463)+(0,145 * 0,581)+(0,099 * 0,541)+(0,089 * 0,564) \quad$ formülüyle $\mathbf{0 , 5 0 3}$ olarak 
hesaplanmıştır. Final puanlar elde edildikten sonra ERP firmalarının aldıkları puanlar karşılaştırılarak alternatiflerin arasından işletmeye en uygun ERP programının satın alınması kararlaştırılmıştır. Alternatif ERP firmaları ile kriterler arasındaki hesaplama sonuçları Tablo 11 de gösterilmiştir. Tabloda görüleceği gibi final puanlarına bakıldığında A firmasının puanının diğerlerine göre çok daha yüksek olduğu görülmektedir. Böylece A firmasının ERP programı işletme tarafindan sonuçlara göre uygun bulunmuş ve sistemin kurulmasına karar verilmiştir.

Tablo 11. Alternatif ERP Sistemleri ağırlıklandırma tablosu

\begin{tabular}{|c|c|c|c|c|c|c|c|c|c|c|c|}
\hline & \multicolumn{2}{|c|}{ Marka İtibarı } & \multicolumn{2}{|c|}{ Teknoloji } & \multicolumn{2}{|c|}{ Fonksiyonellik } & \multicolumn{2}{|c|}{ Maliyet } & \multicolumn{2}{|c|}{$\begin{array}{l}\text { Destek ve } \\
\text { Eğitim }\end{array}$} & \multirow{2}{*}{ 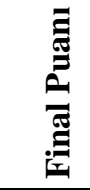 } \\
\hline & Ağırlık & Puan & Ağırlık & Puan & A ğırlık & Puan & Ağgrlık & Puan & A ğırlık & Puan & \\
\hline A Firması & 0,407 & 0,477 & 0,260 & 0,463 & 0,145 & 0,581 & 0,099 & 0,541 & 0,089 & 0,564 & 0,503 \\
\hline B Firması & 0,407 & 0,158 & 0,260 & 0,273 & 0,145 & 0,250 & 0,099 & 0,260 & 0,089 & 0,255 & 0,220 \\
\hline C Firması & 0,407 & 0,233 & 0,260 & 0,169 & 0,145 & 0,125 & 0,099 & 0,140 & 0,089 & 0,131 & 0,182 \\
\hline D Firması & 0,407 & 0,132 & 0,260 & 0,096 & 0,145 & 0,043 & 0,099 & 0,059 & 0,089 & 0,050 & 0,095 \\
\hline
\end{tabular}

\section{SONUÇ VE DEĞERLENDIRME}

Yapılan çalışmada, en çok kullanılan karar verme metotlarından biri olan AHP tekniği kullanılmış ve bir işletmenin alternatif ERP sistemleri arasından literatür ve uzmanların desteği ile belirlenmiş kriterler göz önüne alınarak en uygun alternatifin belirlenmesi sağlanmıştır. Karar verme günlük hayatta birçok konuda karşımıza çıkan ve genelde rutin problemleri kolayca çözebildiğimiz bir işlemdir. Fakat alternatif sayısı ve ele alınan kriterlerin sayısı arttığında problem karmaşıklaşmakta ve çözüm zorlaşmaktadır. $\mathrm{Bu}$ durumda bu tür problemlerin çözümü bilimsel olarak daha önce birçok kez kullanılmış ve sonuçları itibari ile kendini kanıtlamış yöntemlerden biri ile mümkün hale gelmektedir. Bu yöntemlerden en çok kullanılanlarından biri olan AHP tekniği birçok karar verme probleminin çözümünü sağlamıştır. Bu çalışmada alternatif sayısı işlemlerin karmaşıklaşmasını önlemek adına sınırlı tutulmuştur. Fakat gerekirse daha başka alternatif ERP firmaları ile ve farklı kriterler hatta alt kriterler kullanarak yeniden çözüm aranabilir. Her yöntemde olduğu gibi AHP ile karar vermenin de kendine özgü kısıtlamaları olabilmektedir. Bunlardan ilki hesapların karmaşıklığı olarak öne çıkmaktadır. Alternatif ve kriter sayısı belirli sayıda tutulduğu sürece hızlı çözümler üretebilmektedir. Ayrıca kriter belirleme ve uzmanlar tarafından önceliklendirme hassas bir şekilde yapılması gerekmektedir. Hedeflenen amaca ve karar verilecek alternatiflerin özelliklerine göre doğru kriterlerin belirlenmesi çok önemlidir. Ayrıca kriterlerin alanında uzman kişilerce önceliklendirilmesi de sonucu doğrudan etkileyen bir faktördür.

Çalışmada A firması belirlenmiş olan kriterlere göre 0,503 puan alarak en uygun alternatif olarak değ erlendirilmiştir. Diğer dört alternatif ERP sisteminin ise buna göre çok daha az puanlar aldığı görülmüş ve değerlendirme dişı tutulmuştur. Literatürde benzer çalışmalar incelendiğinde kriter sayısı, niteliği ve alternatiflerin farklılıklarına göre bu oranların birbirileriyle daha yakın ya da çok daha farklılaştığı görülmüştür [1],[13],[4],[28].

Çalışmanın hem literatüre katkısı hem de bu amaçla değerlendirme yapmak isteyen işletmeler açısından önemli faydası olacağı düşünülmektedir. Ayrıca çalışmanın ileriye dönük olarak genişletilmesi mümkündür. Kriter seti ve alternatifler arttırılarak farklı sonuçların alınması sağlanabilir. Karar verici uzmanların sayıları ve nitelikleri arttırılarak karar verme sürecinin daha ayrıntılı ve hassas şekilde yapılması için daha ileri çalışmaların yapılabilmesi mümkündür. 


\section{KAYNAKLAR}

[1] Ahn, B.S, ve Choi S. H. (2008), "Erp System Selection Using A Simulation-Based Ahp Approach: A Case Of Korean Homeshopping Company", Journal Of The Operational Research Society, Say1: 59, S.322-330

[2] Bueno, S. ve Salmeron L. J., (2008), Fuzzy Modeling Enterprise Resource Planning Tool Selection, Computer Standards \& Interfaces, Say1: 30, S.137-147

[3] Chou, D. C., Bindu Tripuramallu, H., ve Chou, A. Y. (2005). BI and ERP integration. Information Management \& Computer Security, 13(5), 340-349.

[4] Karsak, E. E.Ve Özoğul, C. O.,,(2009) An Integrated Decision Making Approach For Erp System Selection, Expert Systems With Applications, Say1: 36, S.660-667

[5] Kumar, K. ve Hillsgersberg V.J., (2000), "Erp Experiences And Evolution", Communication Of The Acm, Say1: L:43, (4/23), S. 22-26.

[6] Lin, H. Y.; Hsu, P. Y. Ve Sheen, J. G., (2007), A Fuzzy-Based Decision-Making Procedure For Data Warehouse System Selection, Expert Systems With Applications, Say1: 32, S.939-953

[7] Perçin, S., (2008), Using The Anp Approach In Selecting And Benchmarking Erp Systems, Benchmarking: An International Journal, Sayı: 15 (5) 630-649

[8] Teltumbde, A., (2000), A framework for evaluating ERP projects, International Journal of Production Research, Sayı: 38(17), s.4507-4520

[9] Umble, E. J., Haft, R. R., \& Umble, M. M. (2003). Enterprise resource planning: Implementation procedures and critical success factors. European journal of operational research, 146(2), 241-257.

[10] Ünal, C. Ve Guner, G. M., (2009), Selection Of Erp Suppliers Using Ahp Tools In The Clothing Industry, International Journal Of Clothing Science And Technology, Sayı: 21(4), S.239-251

[11] Wei, C.C., Chien, F. C. ve Wang, J. M. J., (2005), “An Ahp-Based Approach To Erp System Selection, International Journal Production Economics, Say1: 96, S.47-62

[12] Postac1, T., Belgin, Ö., \& Erkan, T. E. (2012). KOBİ'lerde Kurumsal Kaynak Planlamas1 (ERP) Uygulamaları. Verimlilik Genel Müdürlüğü, Yayın, (723), 1-60.

[13] Bayraktar, E., \& Mehmet, E. F. E. (2006). Kurumsal Kaynak Planlamasi (Erp) ve Yazilim Seçim Süreci. Selçuk Üniversitesi Sosyal Bilimler Enstitüsü Dergisi, (15), 689-709.

[14] Dulkadir, B. (2012). Tekstil İşletmelerinde Kurumsal Kaynak Planlaması (ERP) Kullanımındaki Memnuniyet Düzeyi ve Malatya İlinde Bir Araştırma. Akademik Yaklaşımlar Dergisi, 3(2).

[15] Seyrek, İ. H. (2011). Bulut Bilişim: İşletmeler için firsatlar ve zorluklar. Gaziantep University-Journal of Social Sciences, 10(2), 701-713.

[16] Jang, W. Y., Lin, C. I., \& Pan, M. J. (2009). Business strategies and the adoption of ERP: Evidence from Taiwan's communications industry. Journal of Manufacturing Technology Management, 20(8), 1084-1098.

[17] Yang, J. B., Wu, C. T., \& Tsai, C. H. (2007). Selection of an ERP system for a construction firm in Taiwan: A case study. Automation in construction, 16(6), 787-796. 
[18] Evren, R., Ülengin, F. (1992). Yönetimde Çok Amaçlı Karar Verme, İTÜ Yayınlan, İstanbul.

[19] Feng, C.M., Wang R.T, (2000). "Performance Evaluation for Airlines Including the Consideration of Financial Ratios", Journal of Air Transport Management, 6, 133-142.

[20] Dağdeviren M., Akay D., Kurt M. (2004). "îş Değerlendirme Sürecinde Analitik Hiyerarşi Prosesi ve Uygulaması”, Gazi Üniversitesi Mühendislik Mimarlık Dergisi, 19(2), 131-138.

[21] Dinçer H., Görener A. (2011). "Performance Evaluatıon Usıng AHP - VIKOR And AHP - TOPSIS Approaches: The Case Of Service Sector”, Journal Of Engineering And Natural Sciences Sigma, 29, 244-260.

[22] Kaya Y. (2004). Çok Amaçlı Karar Verme Yöntemlerinden TOPSIS ve ELECTRE Yöntemlerinin Karşıllaştırılması, Yüksek Lisans Tez. Havacılık ve Uzay Teknolojileri Enstitüsü, İstanbul.

[23] Saaty, Thomas L., (1980), The Analytic Hierarchy Process, McGraw-Hill International Book Company, New York.

[24] Saaty L. T. (1994) "Highlights and critical points in the theory and application of the Analytical Hierarchy Process”, European Journal of Operational Research, 74, 426-447.

[25] Saaty, Thomas L., (2000), Fundamentals of Decision Making and Priority Theory, 2. Edition, RWS Publications, Pittsburgh.

[26] Golden, L. B. ve Wang Q. (1989b) "An alternate measure of consistency”, Golden, B. L., Wasil, E. A. ve Harker P. T. (der.), The Analytic Hierarchy Process içinde, Springer Verlag, New York, 69-81.

[27] Zadehi, F. (1997) " Reliability metric for information systems based on customer requirements ", International Journal of Quality and Reliability Management, 14 (8), 791-813.

[28] Chin K.S. , Chiu, S. ve Tummala, V. M. R. (1999) " An evaluation of success factors using the AHP to implement ISO 14001-based EMS ", International Journal of Quality and Reliability Management, 16 (4), 341-361.

[29] Ramadhan, R. H., Al-Abdul Wahhab, H. I., \& Duffuaa, S. O. (1999). The use of an analytical hierarchy process in pavement maintenance priority ranking. Journal of Quality in Maintenance Engineering, 5(1), 25-39.

[30] Gungor, I., \& Isler, D. B. (2005). Analitik hiyerarsi yaklasimi ile otomobil secime. ZKU Sosyal Bilimler Dergis, 1(2), 21-31. 